\title{
A techno-economic model-based analysis of the renewable energy transition in the Indian subcontinent region
}

\author{
K. S. Bhat, U. Bachhiesl, G. Feichtinger, H. Stigler
}

\begin{abstract}
India, as a 'developing' country, is in the middle of a unique situation of handling its energy transition towards carbon-free energy along with its continuous economic development. With respect to the agreed COP 21 and SDG 2030 targets, India has drafted several energy strategies revolving around clean renewable energy. With multiple roadblocks for development of large hydro power capacities within the country, the long-term renewable goals of India focus highly on renewable energy technologies like solar Photo-Voltaic (PV) and wind capacities. However, with a much slower rate of development in transmission infrastructure and the given situations of the regional energy systems in the Indian subcontinent, these significant changes in India could result in severe technical and economic consequences for the complete interconnected region. The presented investigations in this paper have been conducted using ATLANTIS_India, a unique techno-economic simulation model developed at the Institute of Electricity Economics and Energy Innovation/Graz University of Technology, designed for the electricity system in the Indian subcontinent region. The model covers the electricity systems of India, Bangladesh, Bhutan, Nepal, and Sri Lanka, and is used to analyse a scenario where around $118 \mathrm{GW}$ of solar PV and wind capacity expansion is planned in India until the target year 2050. This paper presents the simulation approach as well as the simulated results and conclusions. The simulation results show the positive and negative techno-economic impacts of the discussed strategy on the overall electricity system, while suggesting possible solutions.
\end{abstract}

Keywords: Indian subcontinent; electricity system; renewable energy; energy transition; simulation model; COP 21; SDG 2030

\section{Eine technoökonomische modellbasierte Analyse der Energiewende auf Basis erneuerbarer Energien für den indischen Subkontinent.}

Indien ist als "Entwicklungsland" in einer einzigartigen Situation, da eine Dekarbonisierung der Energiewirtschaft bei gleichzeitiger wirtschaftlicher Entwicklung zu erreichen ist. Basierend auf der Zustimmung zu den COP 21- und SDG 2030-Zielen, hat Indien mehrere Strategien in Richtung sauberer erneuerbarer Energien erarbeitet. Durch zahlreiche Hemmnisse bei der Entwicklung neuer großer Wasserkraftwerke fokussieren die Langzeitziele auf die intensive Nutzung von Photovoltaik und Windkraft. Allerdings können die langsame Entwicklung der Übertragungsnetze sowie die Besonderheiten der regionalen Energiesysteme des Subkontinents auch zu hohen technischen und wirtschaftlichen Risiken in der gesamten verbundenen Region führen. Die im Rahmen dieser Arbeit vorgestellten Untersuchungen wurden mit ATLANTIS_India - einem einzigartigen technoökonomischen Simulationsmodell - durchgeführt, welches am Institut für Elektrizitätswirtschaft und Energieinnovation/TU Graz für den gesamten indischen Subkontinent entwickelt wurde. Das Model umfasst die Elektrizitätswirtschaften von Indien, Bangladesch, Bhutan, Nepal und Sri Lanka und wurde für die Untersuchung eines Szenarios verwendet, in welchem die Integration von rund 118 GW aus Photovoltaik und Windkraft beim Systemumbau bis 2050 berücksichtigt wurden. Im Rahmen dieses Artikels werden der Simulationsansatz, die Simulationsergebnisse sowie die daraus resultierenden Schlussfolgerungen präsentiert. Die Simulationsergebnisse zeigen die positiven und negativen Auswirkungen der diskutierten Strategie auf das gesamte Elektrizitätssystem und es werden entsprechende Lösungswege aufgezeigt.

Schlüsse/wörter: Indischer Subkontinent; Elektrizitätssystem; erneuerbare Energie; Energiewende; Simulationsmodell; COP 21; SDG 2030

Received September 12, 2019, accepted October 16, 2019, published online December 5, 2019 (c) The Author(s) 2019

\section{Introduction}

India showed its commitment for the battle against climate change by agreeing to the U.N. Framework Convention on Climate Change (UNFCCC, COP 21) proceedings [16], December 2015. Furthermore, the Goal 7 (Clean Energy), Goal 8 (Economic Growth) and Goal 9 (Infrastructure) of the Sustainable Development Goals (SDG 2030) supported by the United Nations (U.N.) in India focus on a sustainable way to improve access to affordable and clean energy, all the while ensuring economic growth and infrastructure development in the country [1]
The energy system in the Indian subcontinent region is mainly characterized by the energy system of India. When the economic development and the energy usage within a country are coupled to a certain extent, any small change in the overall energy system could

Bhat, Karthik Subramanya, Institute of Electricity Economics and Energy Innovation (IEE), Graz University of Technology, Graz, Austria; BachhiesI, Udo, Institute of Electricity Economics and Energy Innovation (IEE), Graz University of Technology, Graz, Austria; Feichtinger, Gerald, Institute of Electricity Economics and Energy Innovation (IEE), Graz University of Technology, Graz, Austria; Stigler, Heinz, Institute of Electricity Economics and Energy Innovation (IEE), Graz University of Technology, Graz, Austria 
actually result in severe consequences. Furthermore, the economies of several of the countries in the Indian subcontinent (Bangladesh, Bhutan, Nepal and Sri Lanka) are closely related to the economic situation in India. Though India shares borders with Pakistan and China, no significant interactions in the economies and the energy systems exist, due to political and/or territorial conflicts between the countries.

The Indian energy system is characterized by a rapidly growing demand, a huge dependency on coal-fired electricity, and a strong coupling between energy usage and economic development. The immensely growing manufacturing sector in India has a proportionate - if not even higher - growth observed in the energy demand. The process of bringing in an energy transition at this point in India's timeline is severely critical and challenging. However, the energy transition in India is a much-needed process, as the country's emissions not only have local regional effects, but also a significant global impact. India was the third largest emitter of $\mathrm{CO}_{2}$ in 2018 [17] and it is widely agreed, that a global mindset towards battling climate change is of utmost importance.

\section{The Indian Electricity Sector}

The electricity sector in India forms a major part of its energy system. As of the year 2018, with 1423 TWh of electricity generation [3], India is the world's third largest electricity producer, only after China and the United States. India's electricity sector is well known for its huge dependency on coal - around 65 percent of the country's generated electricity was from coal-based generation capacities in 2018. Moreover, the carbon-based emissions of the Indian electricity system stem mainly from its large coal-fired fleet. India's coal fired generation fleet has been continuously growing since the economic reforms in the early 1990s, even more after the partial liberalization of the energy market in the country in 2003 (Central Electricity Act [18]). After the country's agreement to the COP 21 proceedings and the SDG commitment goals, India, after a long time has turned its focus on alternative and renewable energy (RE) technologies like solar PV and wind energy technologies. This initial step in the diversification of the power plant portfolio leads to a strong belief that the country is serious about bringing in the green energy transition. As of 2017, the capacity of non-fossil fuel-based electricity generating capacities has grown by 51.3 percent [4], and a more than doubling of RE capacity (PV, wind, biomass and small hydropower) from 2014 is reported, showing the country's commitment towards the SDGs

A model-based approach gives a much-needed understanding of the electricity system in the sub-continent region, and creates an opportunity to check the compatibility between the energy politics in the region and the overall system performance. This also brings in a sustainable way for planning of the energy transition process. The economic part of the model-based approach points out the economic feasibility of the defined transition scenario, thus covering both the technical and the economic requirements for the evolution of a sustainable electricity system.

\section{Renewable energy and long-term planning in India}

To keep true its commitment to its agreement on the curtailment of 30 percent of its carbon-based emissions by 2030, the Government of India (Gol) announced an ambitious plan of increasing its installed Variable Renewable Energy (VRE) capacity to $175 \mathrm{GW}$ by the year 2025. In terms of this goal, the Gol has already made several large installations of PV (20 GW) and onshore wind capacities (15 GW), and has introduced several subsidy schemes like better feed-in tariffs and lower interest rates to promote private investments (b).
However, several studies $[5,6]$ show that a large increase in RE penetration is not essentially a great strategy, considering the effect of the intermittent nature of the VRE technologies like PV and wind on the transmission system.

India has a large technical potential for PV and onshore wind generation. A study from the National Institute of Solar Energy (NISE) [7] estimates the overall technical potential for PV to be around 748 GW, distributed almost throughout the country. According to studies by the National Institute of Wind Energy (NIWE), India also has an estimated technical onshore wind potential of $103 \mathrm{GW}$ at $80 \mathrm{~m}$ and around $50 \mathrm{GW}$ at $50 \mathrm{~m}$ heights. With an estimated potential of $127 \mathrm{GW}(\mathrm{d})$, offshore wind development in the country however, has a much slower progress. Though India has one of the largest coast lines in the world, the eastern coast is seasonally affected by severe storms and cyclones due to the unique geographical irregularity there. Several development zones in the West (70 GW potential) and the South (60 GW potential) have been defined, and an initial capacity of around $6 \mathrm{GW}$ has been planned on a long-term basis, by the year 2035 [8].

Large hydro power development within the country has met with a roadblock, due to various social, political and environmental issues. However, studies [5] show that hydro power, being a Dispatchable Renewable Energy (DRE) technology, is much needed, mainly to mitigate the so-called 'integration' costs resulting from a high penetration of VRE technologies into the electrical grid. Though development of large hydro within India has reached a standstill due to several territorial, water-sharing and migration disputes, several workarounds have been proposed. The development of Small Hydro Power or Micro Hydro Power in the country has been heavily subsidized, and a technical potential of $150 \mathrm{GW}$ [9] has been identified. Also, bilateral agreements with neighbouring countries of Bhutan and Nepal also lets India finance, build and partially loan its new large hydro capacities, mutually benefitting all involved parties. Majority of India's planned large hydro installations after the year 2030, are proposed in the Bhutanese and Nepalese regions. The long-term renewable energy planning by the Gol within the country hence is much more focused on PV and wind capacity expansions, with their available potentials large enough to solve India's electricity related challenges in the coming future.

\section{Techno-economic model ATLANTIS_India}

ATLANTIS_India [2] is a techno-economic model developed for the Indian sub-continent region at the IEE, Graz University of Technology. The work surrounding the design and development of the model was elaborate, considering the highly specific technical details and the geographical accuracy involved within. The model is closely based on the techno-economic model ATLANTIS [10], also developed at IEE, for the simulation of the European energy economics. The model ATLANTIS_India covers the five different power regions in India: East Region (ER), North East Region (NE), North Region (NR), South Region (SR) and West Region (WR), along with the regions of Bangladesh (BA), Bhutan (BH), Nepal (NP) and Sri Lanka (SL). The electricity sectors of BA, BH, NP and SL regions have/will have close interactions with the Indian electricity economics.

The simulation model is characterized by a physical technical layer, along with an economic layer, thus making it a techno-economic model. The physical layer consists of technical elements like demand centres/substation nodes, transmission lines, transformer stations, power plant park and several other components of the power system. ATLANTIS_India consists of more than 3000 nodes with nodespecific demand distribution, over 6200 transmission lines with physical restrictions, and over 4000 power plants with different technology types and their specific parameters like efficiency, availability 


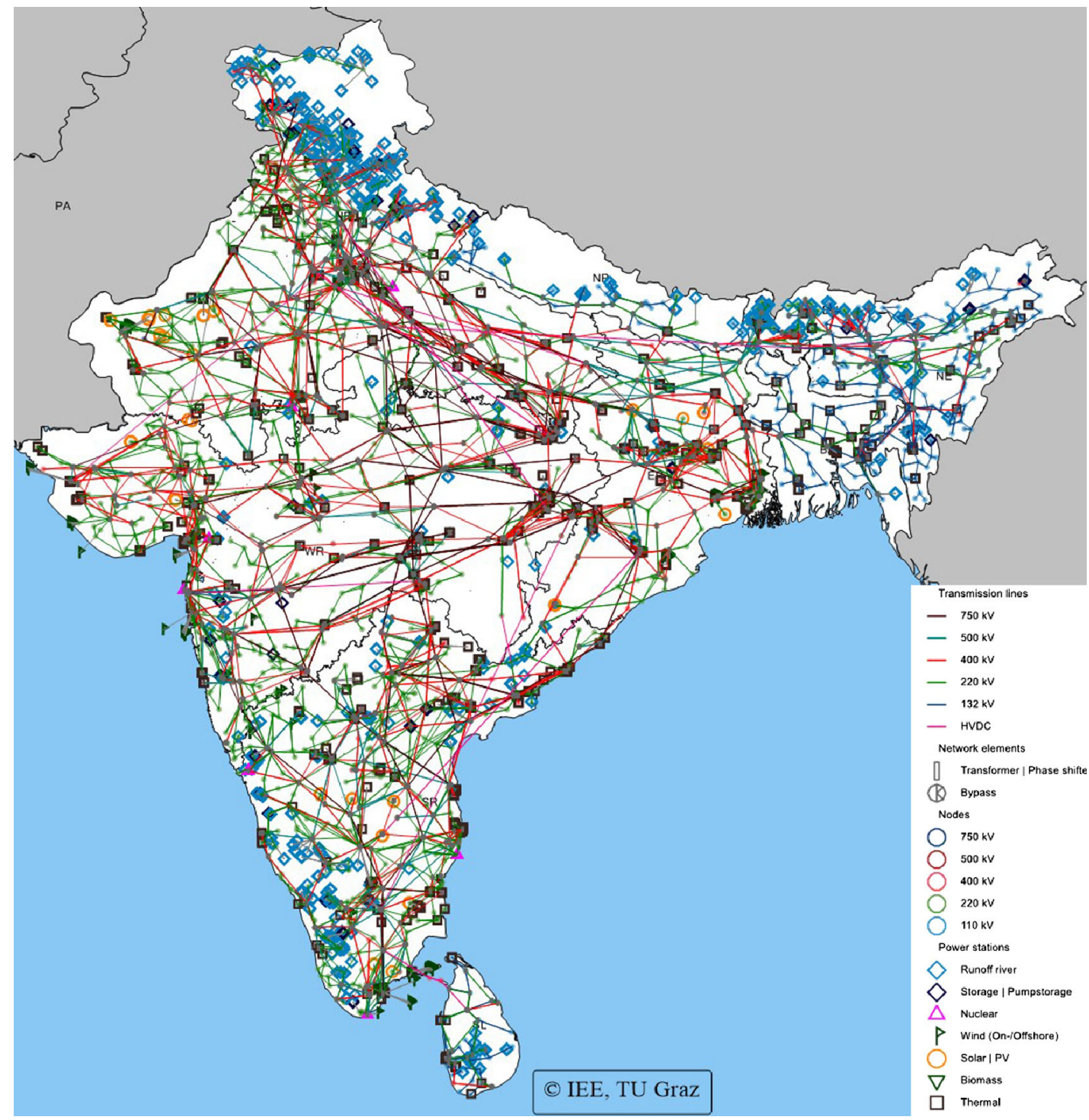

Fig. 1. Visualization of the physical layer in the simulation model ATLANTIS_India (Color figure online)

factors and ownership company information. Furthermore, the additional demand resulting from various causes (e.g. electromobility, power demand management, etc.) can also be integrated into the model, if and when necessary. The physical layer showing all the technical components is visualized in the model as shown in the Fig. 1.

The simulation mechanisms included in the simulation model are based on four different market model types - the basic copper plate 'Energy Exchange Market' (EEM) model, the 'Zonal Pricing' (ZP) model, the 'Overall Market' (OM) model and the 'Redispatch Zonal Pricing' (RDZP) market model.

The basic EEM assumes a large copper plate on which the model regions lie, so no restrictions to power exchange between regions are assumed. The intersection between the regional demand and supply curves represents the cost-minimizing price. In the ZP model, the demand-supply curve intersection also decides the costminimizing price, albeit with the existing Net Transfer Capacity (NTC) based trading restrictions between the model regions, bringing in an NTC-based market coupling approach.
In the ZP model, the interconnected regions trade energy from cheaper to more expensive regions, whose energy export/import capacity is subject to the NTC restrictions. The market coupling between the model regions is designed for a zonal approach, and is based on an implicit auction mechanism. The main results of the market coupling are unit dispatch, the import-export balances of each bidding zone, and the zonal prices of the electricity. The OM model calculates the cost-minimizing price and the regional electricity production values by including the physical restrictions in the transmission lines, available capacities and the node-based electricity distribution. The load flow calculations here are based on DC load flow, using the DC-Optimal Power Flow (DC-OPF) method $[10,11]$.

The RDZP model, is the most complex and the most realistic market model type in ATLANTIS_India, with the inclusion of both load flow calculations and NTC-based trading restrictions. The RDZP model can be said to be 'interconnected' with the ZP model, where the final trading results from the NTC-based market coupling in the ZP model are included. In the subsequent step, the market model 
results and the resulting unit dispatch are evaluated in terms of load flow calculations based on the DC-OPF method.

The RDZP model, like all the other market models in ATLANTIS_India as mentioned, follows a cost-based optimization procedure. Along with the NTC based market coupling algorithm (cross border constraints), the objective function is defined as the maximization function for the economic welfare by minimization of overall generation costs, from an electricity economics perspective. The welfare-maximization function is described as follows:

$$
\begin{aligned}
& \max _{q D, q S}\left\{\sum_{i}\left[\sum_{n}\left(q D_{n, j} \cdot p D_{n, i}\right)-\sum_{a}\left(q S_{a, i} \cdot C_{v a r} S_{a, i}\right)\right]\right\} \\
& \text { s.t. } q S_{a, i} \leq q S_{\max _{a, i}} \\
& \quad q D_{n, i} \leq q D_{\max _{i, i},} \\
& \quad \text { export }_{i \rightarrow j}-\text { import }_{i \rightarrow j} \leq N T C_{i \rightarrow j} \quad \forall(i, j \mid i \neq j) \\
& \quad \sum_{k} \text { export }_{k \rightarrow j}-\sum_{k} i m p o r t_{k \rightarrow j} \leq T P_{k \rightarrow j} \quad(k \subset i \wedge j \notin k) \\
& \quad \sum_{a} q S_{a, i}-\sum_{n} q D_{n, i}+\sum_{i \neq j} \text { import }_{i \rightarrow j}-\sum_{i \neq j} \text { export }_{i \rightarrow j}=0 \quad \forall i
\end{aligned}
$$

with:

$$
\begin{array}{ll}
i, j: & \text { bidding zones, market areas } \\
k: & \text { defined technical profiles between market areas } \\
n: & \text { block bid of demand } \\
a: & \text { block bid of supply } \\
q D_{n, i}: & \text { cleared part of demand block } n \text { in market } i(\mathrm{MW}) \\
q S_{a, i}: & \text { cleared part of supply block a in market } i(\mathrm{MW}) \\
p D_{n, i}: & \text { demand price }(€ / \mathrm{MWh}) \\
C_{v a r} S_{a, i}: & \text { marginal costs of supply block a in zone } i(€ / \mathrm{MWh}) \\
i m p o r t_{i \rightarrow j}: & \text { import in market } i \text { from market } j(\mathrm{MW}) \\
\text { export }_{i \rightarrow j}: & \text { export from market } i \text { to market } j(\mathrm{MW}) \\
N T C_{i \rightarrow j:}: & \text { net transfer capacity between market } i \text { and } j(\mathrm{MW}) \\
T P_{k \rightarrow j}: & \text { technical profile between marketset } k \text { and } j(\mathrm{MW})
\end{array}
$$

ATLANTIS_India also features capital stock calculations for power plant fleet evaluations as well as profit and loss statements and financial balances for over 200 defined power plant owner companies. The economic evaluation also strives to be realistic, with the inclusions of time series of several factors like interest rates, inflation rates, depreciation rates, primary energy price indexes and many more economic parameters in the calculations.

For the scope of this paper, the RDZP market model type is used to simulate an as-close-to-reality-as-possible scenario for the defined RE strategy, for the Indian subcontinent until the target year 2050.

\section{Scenario definition in ATLANTIS_India}

The scenario defined in this paper deals mainly with the expansion of VRE capacity in India, and the several techno-economic effects on the overall electricity system have been analysed. Around $118 \mathrm{GW}$ of VRE capacity additions to the Indian power plant fleet have been introduced, including the refurbishment of RE capacities (at the end of their technical lifetimes) within the target year 2050. Overall, a total of $88 \mathrm{GW}$ of solar PV and $30 \mathrm{GW}$ of on- and off-shore wind capacities forms a large share in the Indian power plant fleet, in the year 2050.

Allocation of new VRE capacity in the scenario has been done completely based on identified technical potentials by NISE [7], by NIWE $[8,19]$, available transmission infrastructure $[2,21]$, and it is observed to be concentrated mainly in the NR, SR and WR regions. Offshore wind development zones in the WR and SR regions are also utilized in this scenario, and over $6 \mathrm{GW}$ of offshore wind capacities have been added at planned specific locations in the drafted

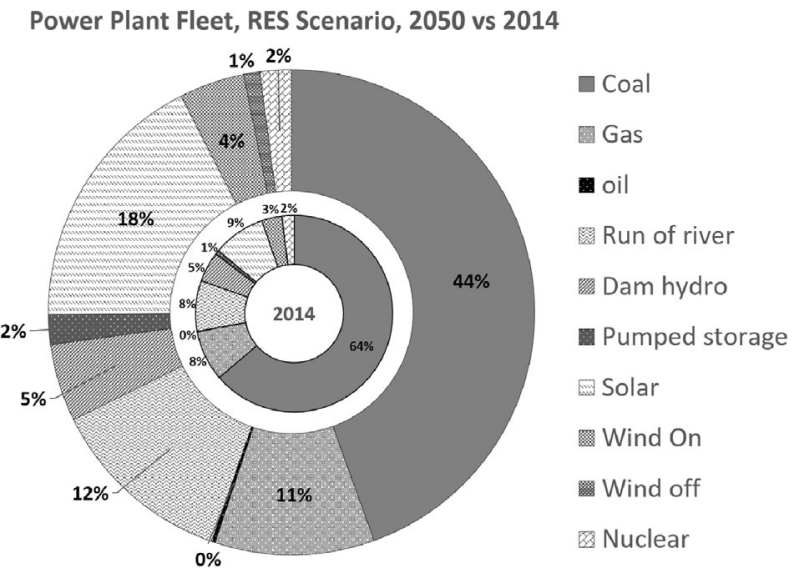

Fig. 2. Comparison of the scenario capacity mix of the power plant fleet in the Indian subcontinent region with actual 2014 values

development zones. To check the effectiveness of the VRE expansion strategy, the addition of new coal-fired capacities is completely neglected in this scenario, and most of the existing older coal-fired capacities are replaced by relatively ( $60 \%$ ) smaller Combined Coal and Gas Turbine (CCGT) capacities with high operating efficiencies at the end of their technical lifetimes. These assumptions are in regards to avoid the stranding of the existing coal-fired assets and in relation to the published estimates of India's Natural Gas demand doubling by the year 2030 [12]. The proposed large hydro capacity expansions by the Gol in the $\mathrm{BH}$ and NP regions, though only till the year 2030 have been considered in this scenario. Simulations until the target year are carried out for the RDZP market model, till the year 2050 and subsequent conclusions are drawn from the simulated results. A build-up of the power plant fleet in the target year 2050 defined in the scenario is shown in the Fig. 2.

The improvement of energy efficiency is heavily supported in this scenario, and all the energy efficiency directives [20] by the Bureau of Energy Efficiency (BEE), Gol are assumed to be implemented by the year 2030. An almost saturation of the electricity demand growth was observed in the demand projections in the later stages of the simulation timeline. The total installed capacity in the defined scenario totals to around $550 \mathrm{GW}$.

\section{Results}

ATLANTIS_India provides a wide spectrum of simulation results, and the analysis of these results leads to effective inferences. The 'loading' of the lines in the transmission network provides an estimation of sufficient/insufficient transmission infrastructure, the electrical energy generated and the resulting emissions represents a quantification of the effectiveness of the added capacities, and the zonal prices/capital stock gives the measurement of economic impact.

The bottlenecks in the existing transmission network resulting from the addition of large VRE capacities in specific regions are observed at all voltage levels in the transmission network. The major bottlenecks, with respect to the resulting load flows, are observed mainly in the $220 \mathrm{kV}$ network (feed-in of VRE mostly at $220 \mathrm{kV}$ level), and the cross-border transmission lines (import/export).

These bottlenecks result in Re-Dispatch, bring about a reduced generation from the planned VRE capacities, and is observed to be compensated by a significant increase in generation from the CCGT capacities closer to the demand centers. 


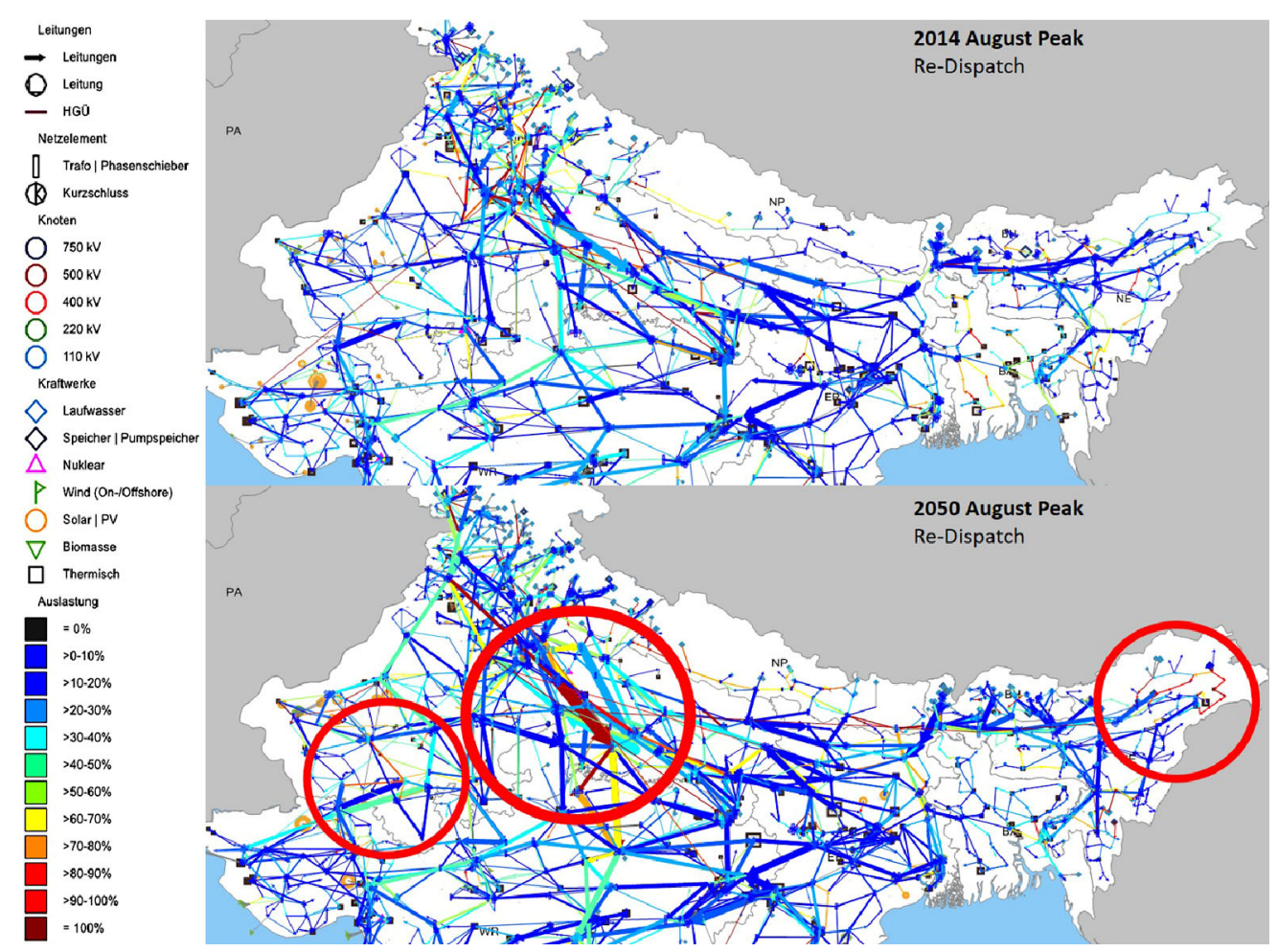

Fig. 3. Load flow comparisons and bottlenecks (black) in the $220 \mathrm{kV}$ and CB network in the Northern part of India during the peak period of August 2014 and in 2050 (Color figure online)
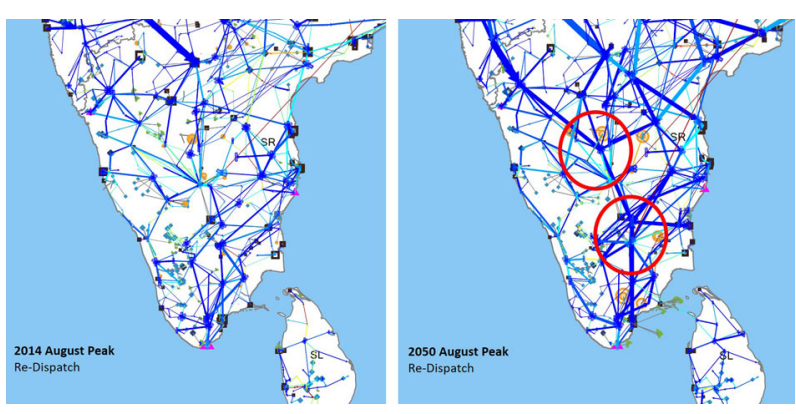

Fig. 4. Load flow comparisons and bottlenecks (black) in the $220 \mathrm{kV}$ and CB network in Southern part of India during the peak period of August 2014 and in 2050 (Color figure online)

The accompanying Figs. 3 and 4 show the simulated load flows in the transmission network in the target year 2050, compared with the load flows in the base validation year 2014. The bottlenecks in the transmission system can be easily identified, especially around the VRE feed-ins, and either transmission reinforcement or construction of a new line can then be planned strategically around the identified bottleneck.

The simulated electricity prices are calculated based on the cost optimization in the RDZP market model, for the different model regions, along with the export and import values between the regions. Without a planned reinforcement of transmission infrastructure, this scenario strategy would result in the CCGT capacities producing more electricity, as discussed previously (due to the observed bottlenecks in the transmission network). An overall increase in the zonal prices is thus mainly observed because of the increasing nature of the fuel prices (Coal and Natural Gas), and also because the region still depends highly on 'steady' electricity generated by the CCGT replacements.

As another example of the economic evaluation, a Fig. 5 illustrates the net capital stocks (after consideration of depreciation and technical lifetimes) of the power plant fleet of each region in the model, depicting the estimated 'wealth' of their respective power sectors in the year 2050. A large increase in net capital stocks is observed in the $\mathrm{BH}$ and NP regions, especially with the increase in hydropower plant capacity by the $\mathrm{Gol}$ in these regions.

\section{Conclusions}

Several conclusions are drawn from the simulated results, for the VRE based scenario defined in the scope of this paper. Firstly, it can be observed that the VRE additions create several bottlenecks in the $220 \mathrm{kV}$ transmission network, especially around their feed-in nodes. This results in Re-Dispatch, causing reduced generation from these capacities, compensated by an increased generation from the implemented CCGT replacements. Hence, it is reasonably concluded that transmission reinforcement or planning of new transmission infrastructure is absolutely necessary, especially around the planned VRE capacities. This conclusion can be supported by the argument that the VRE capacities in the SR region show better generation values and smaller bottlenecks (Fig. 4), in comparison to the WR and NR regions, due to the availability of new transmission infrastructure in the $220 \mathrm{kV}, 400 \mathrm{kV}$ and $765 \mathrm{kV}$ levels. The HVDC lines planned throughout the subcontinent region also seem to be highly effective.

Secondly, in comparison to the average market price (Marginal Price), there is a decrease in prices in the more expensive regions like $B A, E R$ and $W R$, while there is a slight increase of price in the regions like $S R, N R$ and NE. This would mean that the expansion of the RE capacity would definitely bring overall benefits and welfare 


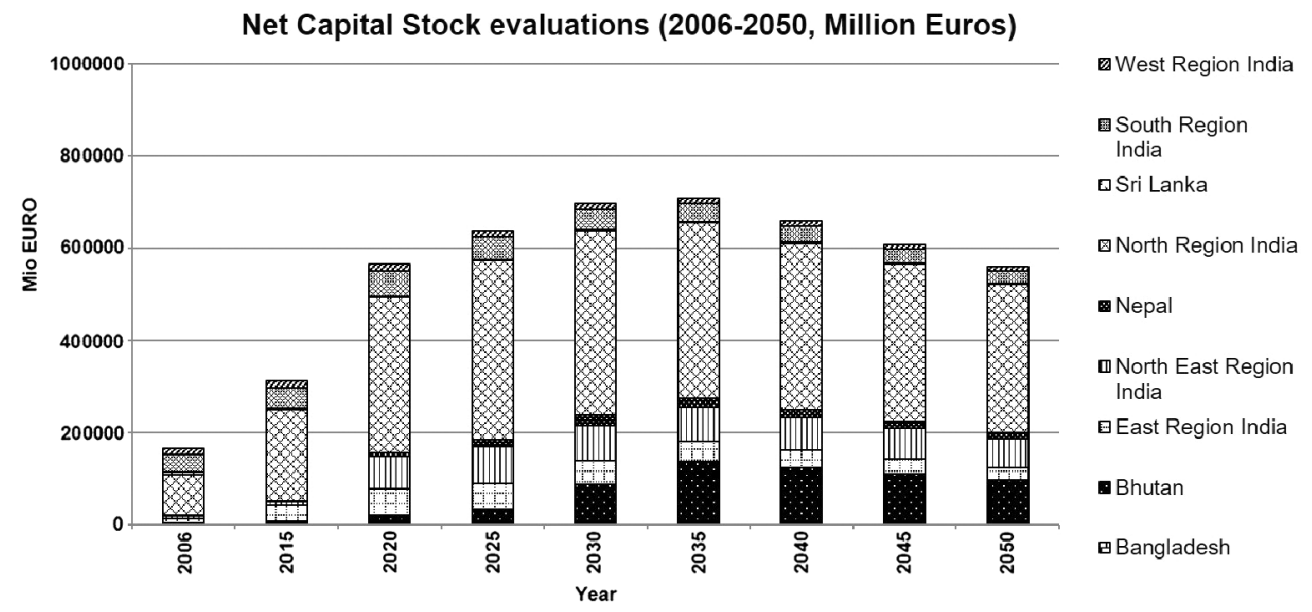

Fig. 5. Net capital stock calculations for the power plant fleet in the Indian subcontinent region until the year 2050

in the several expensive regions on the long term. The regions of $\mathrm{BH}$ and NP profit the most with the higher prices in NR and NE regions, by exporting larger shares of electricity from their hydro capacities to the Indian regions.

Lastly, while on the topic of economic welfare, a large growth in the net capital stock of every region is observed, with hydropower capacities largely contributing with their large capacities and long technical lifetimes. A large increase of the net capital stock of the BH and the NP regions observed from the year 2030 could really bring about social and economic welfare in the regions, all the while supporting the VRE generation in the Indian regions. Thus, along with the current VRE expansion strategy, the further expansion of hydro capacities by the Gol in $\mathrm{BH}$ and NP should also be highly promoted, as the generation from these hydro capacities benefits both India, and the $\mathrm{BH}$ and $\mathrm{NP}$ regions.

\section{Discussion}

Another important aspect to be observed in detail is the resulting $\mathrm{CO}_{2}$ emission values from the generation by the power plant fleet defined in the scenario. The $\mathrm{CO}_{2}$ emissions of all the Indian regions combined in the year 2050 is calculated to as low as 300 Million Tonnes of $\mathrm{CO}_{2}$, which is significantly lower than projected values in several low carbon scenario studies [13]. This is mainly due to the implementation of automatic refurbishments of each solar PV and wind capacities defined in the scenario, and due to almost no new coal-fired capacity additions. The implementation of the strategy of replacing shut-down coal fired capacities by CCGT capacities with much lower defined carbon intensities is also another probable cause. A much more detailed study on the emissions could be done with the model ATLANTIS_India, by integrating the electromobility strategies and the resulting additional load [14] in the subcontinent region. A study to analyse the additional load from electromobility [15] showed that with several off-peak charging strategies, the resulting additional load from an increased share of electric cars in the year 2040 increased the peak electricity demand in the range of 4-10 percent in the various power regions in India.

The spotlight eventually but finally falls on the importance of energy efficiency, because a significant decline in the ever-increasing rate of the growth in annual electricity demand is observed in the evolution of electricity demand. This is even with the demand growth linearly distributed at all nodes based on their relative weightage, inclusive of the increase in specific demand weightages at particular demand centers. The assumptions of the implementation of the improved energy efficiency directives in the scenario build up, as defined by the BEE, Gol prove to be significantly effective.

\section{Acknowledgements}

Open access funding provided by Graz University of Technology.

Publisher's Note Springer Nature remains neutral with regard to jurisdictional claims in published maps and institutional affiliations.

Open Access This article is distributed under the terms of the Creative Commons Attribution 4.0 International License (http://creativecommons.org/ licenses/by/4.0/), which permits unrestricted use, distribution, and reproduction in any medium, provided you give appropriate credit to the original author(s) and the source, provide a link to the Creative Commons license, and indicate if changes were made.

\section{References}

1. NITI Aayog Gol (2017): On the implementation of sustainable development goals. Voluntary national report. India, July 2017.

2. Bhat, K., Feichtinger, G., Bachhiesl, U., Stigler, H. (2018): Model based analysis of the Indian electricity economics. In 15. Symposium Energieinnovation. February 2018.

3. Central Electricity Authority Gol (2018): Growth of electricity sector in India from 1947-2018. Report. June 2018.

4. Ministry of New and renewable Energy Gol (2018): Power from renewables, Chapter 3. Annual Report 2017-18.

5. International Renewable Energy Agency (2015): From baseload to peak: renewables provide a reliable solution. Working paper.

6. Papaefthymiou, G., Grave, K., Dragoon, K. (2014): Flexibility options in electricity systems - Ecofys.

7. National Institute of Solar Energy, Ministry of New and Renewable Energy, Government of India (2012): State wise estimated solar power potential in the country. Report No. 22/02/2014-15/Solar-R\&D (Misc.).

8. Alluri, G., et al. (2017): Offshore wind feasibility study in India. In Stability control and reliable performance of wind turbines. https://doi.org/10.5772/intechopen.74916.

9. Sharma, N. K., Tiwari, P. K., Sood, Y. R. (2013): A comprehensive analysis of strategies, policies and development of hydropower in India: special emphasis on small hydropower. Renew. Sustain. Energy Rev., 18, 460-470.

10. Stigler, H., Bachhiesl, U., Nischler, G., Feichtinger, G. (2015): ATLANTIS: technoeconomic model of the European electricity sector. Cent. Eur. J. Oper. Res. https://doi. org/10.1007/s10100-015-0413-8.

11. Stott, B., Jardim, J., Alsac, O. (2009): DC power flow revisited. IEEE Trans Power Syst, 24(3). https://doi.org/10.1109/TPWRS.2009.2021235.

12. Petroleum, Gas Regulatory Board, N. (2013): Vision 2030 - natural gas infrastructure in India. Report. Industry Group. May 2013.

13. Gambhir, A., Anandarajah, G., et al. (2013): India's $\mathrm{CO}_{2}$ emissions pathways to 2050 . Report GR5. Grantham Institute for Climate Change. January 2013. 
14. Beerman, J., Huber, S., et al. (2012): e-mobility 1.0 - Herausforderungen für eine großvolumige Einführung von Elektrofahrzeugen in Österreich - Auswirkungen auf das Elektrizitätssystem, Batterieladesysteme und Reduktion von Emissionen. June 2012.

15. Bhat, K., Bachhiesl, U., Feichtinger, G. (2017): Role of electromobility in India's renewable scenario 2050. In 10. Internationale Energiewirtschaftstagung an der TU Wien (IEWT). February 2017.

16. https://wri-india.org/events/unfccc-cop21.

\section{Authors}

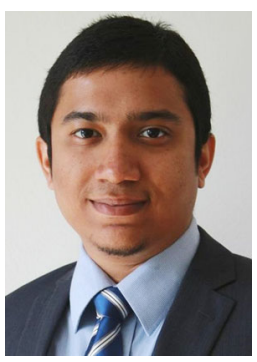

\section{Karthik Subramanya Bhat}

is from Manipal, India. He has a Bachelor of Engineering degree in Mechanical Engineering from the Visveswaraya Technological University, India (2010) and a Master of Science degree in Power Engineering from the Technical University Munich, Germany (2013). He is currently a University Assistant and a PhD student at the Institute of Electricity Economics and Energy Innovation, Graz University of Technology, and specializes in energy transition scenarios for the Indian Subcontinent region. His research interests are in the areas of renewable energy, techno-economic analysis of sustainable energy systems and energy innovation.

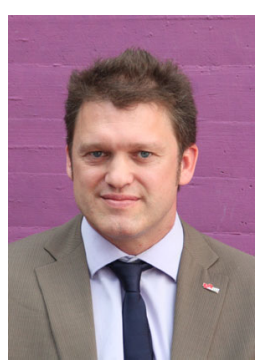

\section{Udo Bachhies}

studied Energy Economics at Graz University of Technology. During his scientific career Dr. Bachhiesl had research stays in Switzerland and France and gained working experience in the energy department of the federal state Styria/Austria. After completing his PhD and habilitation in the fields of energy innovation and energy economics Dr. Bachhiesl is at the moment deputy-head of the Institute of Elec tricity Economics and Energy Innovation at Graz University of Technology. Dr. Bachhiesl is an expert in the field of energy and electricity economics, renewable energies and energy innovation.
17. http://www.globalcarbonatlas.org/en/CO2-emissions.

18. https://asia.nikkei.com/Opinion/Rewiring-Indian-electricity.

19. https://niwe.res.in/department_wra_est.php.

20. https://beeindia.gov.in/content/about-bee.

21. https://www.powergridindia.com/sites/default/files/All-India-Map_SR_WR_ER_NER _NR_UPDATED-Apr\%2717.pdf.

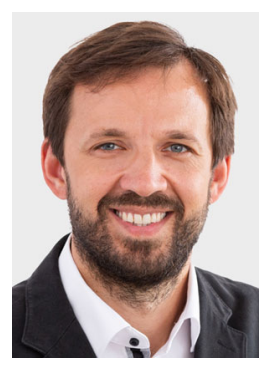

\section{Gerald Feichtinger}

is the business head of the knowledge discovery area at KNOW-CENTER since 2018. He obtained his $\mathrm{PhD}$ in economics from the University of Graz in 2017 with a dissertation on the evaluation of the social economic implications of a European energy transition. His previous research covers multi-regional inputoutput modelling, time series forecasting as well as techno-economic electricity modelling at the Institute of Electricity Economics and Energy Innovation/TU Graz. Dr. Feichtinger received the Austrian Energy Award for his $\mathrm{PhD}$ thesis in 2018 and an award (scholarship) for his master thesis in 2011. Since 2018 he is the co-chair of the task force "i-Spaces" (TF.SG4) at the Big Data Value Association (BDVA) in Brussels.

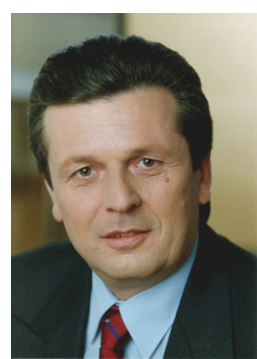

\section{Heinz Stigler}

studied electrical engineering at TU Vienna and economics at WU Vienna. After his engagement as research assistant at the Institute of Energy Economics at TU Vienna Prof. Stigler worked at Verbund AG in Vienna and became CEO of the Steiermärkische Elektrizitäts-AG in Graz. Since 2000 Heinz Stigler has been Professor for Electricity Economics and Energy Innovation at Graz University of Technology. Between 2006 and 2013 he was Dean of the Faculty of Electrical and Information Engineering and since October 2019 Prof. Stigler is emeritus Professor. 